\title{
Impact of Information System and Blockchain on Organizational Learning Effectiveness
}

\author{
https://doi.org/10.3991/ijet.v15i11.12693 \\ Jamshid Ali Turi \\ Department of Management Sciences, \\ SZABIST Larkana Campus, Larkana, Pakistan \\ Alaeldeen Al Adresi ${ }^{(凶)}$, Mohd Ridzuan Darun, Fatimah Mahmud \\ University Malaysia Pahang, Kuantan, Malaysia \\ aladdinxidrisi@gmail.com
}

\begin{abstract}
Focus of the paper was to investigate the impact of information system and blockchain technology on organizational learning effectiveness. Data was collected from the information system faculty and administrative staff of two different universities in Pakistan. Qualitative approach was used to get the objectives of the study. The paper discovered why and how faculty and administrators show resistance or exert influences or assist information system and block chain initiatives in organizational learning effectiveness and sustainability. Qualitative approach was used in the study to comprehend the recurring phenomenon. Finding of the research demands the support of the senior faculty members, administrators and most importantly of the leadership, in the design, orientation and implementation of information system and blockchain for the organizational learning effectiveness.
\end{abstract}

Keywords - Information System; blockchain technology; organizational learning; learning organization; university.

\section{Introduction}

Universities, being learning organizations, in the developing country like Pakistan, consume most of the developmental and operational funds from the government budget. $21^{\text {st }}$ centuries changed the learning phenomenon due to the infusion of information system and block chain technology in working environment. Many internal and external stimuli are putting pressure on the learning organization like university to think and devise new ways of learning and capturing knowledge. Moreover, current century also demands for cost-effective and durable projects with efficient and productive mechanism [1-3]. These efforts have been started from many decays, in Pakistan, to introduce sustainable educational project and policies, through Higher Education Commission (HEC), empowering universities. Especially in Musharaf's era, cost effectiveness, production-based educational plans were designed for quality improvements and transparent accountability practices through performance, monitoring and evaluation measures 
focusing on targets achievement, organizational learning and development, workplace innovations that involve human capital, leadership and quality enhancement initiatives for sustainable educational development and effectiveness.[2, 4-7]. One such educational reforming strategy has been the placement of the information system (IS) and block chain technology for capturing, restorations, contextualization and interpretation of the institutional knowledge [2, 7]. Information system and block chain were deployed with presumptions of its capacity and capability for capturing and dissemination of individual knowledge, experiences and skill, as proved in the success of many industrial projects[2]. Practices and research findings indicates that block chain technology and information system has improved the learning and decision making processes among the organizations $[8,9]$. While some research analysists question the usefulness of information system and block chain technology in educational domain, especially focusing on organizational learning and sustainability[10]. Some researchers proclaims that information system and block chain technologies ingenuities can be encouraging if academicians are engaged, trained, managed and equipped with essential information system skills[3]. Moreover, researcher also suggests that, for unionized, rigid minded and social sciences faculty members may create bottlenecks in the smoother installation and implementation of information system and block chain technology services, as they may not be ameliorated with it and may not fully engaged organizational learning processes[11, 12].

Conflicts in opinions, interests and procedure are natural and norm of the complex and pluralistic organizations[6]. Therefore, attempt to change the existing phenomenon, even in futuristic and learning organizations become bit difficult, because every stakeholder maintained different approach and preferences[13]. Educational professionals, particularly faculty members and administrators in universities, are too influential and can pave and change the road for the adaptation of information system and block chain technology for learning, novelties, change and effectiveness[12]. Researchers argue that always organizational change has been resisted by their member, which has been named as organizational cynicism, because it challenges professional engagement and dominance of the members, autonomy and managerialism $[14,15]$. However, university faculty' readiness to accept modification and change in form of organizational innovation, such as deployment of information system and block chain technologies, especially in Pakistan, have no history and has not been managed and documented. Therefore, main focus of the paper is to explore the phenomenon, that how universities leaders can embed learning novelties and change in the teaching-learning processes, capturing and contextualizing the organizational knowledge and learning through information system and block chain initiatives for sustainable organizational learning and development. Our main focus of interest was to find out the role of faculty members and university's leaders in the promotion of work place innovation, acceptance of the information system and block chain technologies and engagement of the knowledge workers in the promotion of these technologies orientation, persuasion and convincing. At the same time, it also assesses the resistance to this change in response to the orientation of technology in organizational learning and development.

The concept of Institutional Work (IW) by Lawrence and Suddaby's [16] and the sociology of occupations fiction and learning (Lansbury, 1978) was made as a foundation 
for the exploration of the learning phenomenon in the learning organizations like universities. Via these theory, faculty members role as 'institutional agents' during the introduction and orientation phase of the information system and block chain technology initiative was explored and this procedure was in line with[17]. Faculty members and administrators are the major stakeholders of the universities and they are the main change agents, who can give new directions, new resolutions, new enthusiasms, new philosophies and new ways of working in university, to their fellows, students and peer[ $[11,15,18-20]$. We ask why and how faculty and administrator paly their role in the change acceptance or showing resistance; persuasion and enabling technology initiatives in learning organizations like universities. For answering these questions, we scrutinize a study of information system and block chain technologies interventions in two Information System (computer Science) departments in two major universities in Pakistan, one from public and one from private sector. There are similarities in the orientation, operations and management and that of information system and other technologies usage that make this a valuable comparison. We discovered how faculty members cooperate with other learning actors such as faculty members, students and managerial staff at three levels. We focus on cognitive, social and behavioral learning. In the first attempt we first explore and studied the cognitive aspects of human and organizational learning and we focused on accumulated both tacit and explicit knowledge, skill and experiences in acute and secondly the data was collected from operators of the information system who were focusing on the attitude and behaviors of the high profile faculty members and IS was used to record all the happenings of the phenomenon [21]. Our research extended Lawrence and Suddaby's [16] typology of IW to the learning organization like university. We studied that what change agents do when they are involved in IW procedures, processes and operations and the collaboration of learning factors and knowledge workers at different level. Moreover, we searched how the knowledge worker and professional occupational status influences on the process of generating, preserving and also distracting organizational learning elements in the learning organizations, keep in view the resisters and organizational interests. We build on the work of L.Vargoa, Meliss, \& Akak [22] by using IW to explore how senior faculty members control is maintained in our investigation of how faculty use and adapt IS to maintain their own and organizational learning and development. We recognize that many faculties members are in 'hybrid' roles, that is they are knowledge workers who hold managerial, leadership and instructional responsibilities' [12, 23]. Thirdly, we also kept close eyes on the previous research findings, which were not in favor of information system installation and its implementation for promoting organizational learning and development[15], through the finding of this paper, we contributed to the institutional work theory and the sociology of learning and practice that information system has the capacity and capability of promoting, capturing, sharing and disseminating organizational and individual knowledge and it can be best used for organizational learning and development and can be embedded in learning processes inside the learning organization like universities.

In the study, first empirical data and evidences on the implementation of information system and block chain technology in universities and their impact on employee's per- 
formance were collected from the knowledge workers and faculty members and administrators for individual and organizational learning and development. At the second stage, we detailed literature review and content analysis on the sociology of learning and IW theory and its relevance for understanding such knowledge capturing and dissemination issues in universities. Moreover, we also considered the organizational domain and environment for the interpretation of the captured knowledge, their interpretation in the organizational needs and requirements, and then, introduce the main agents of learning, which may be named as knowledge workers. Fifth, we outline our methodology. Finally, we compared the working environments and their prevailing situation thoroughly for drawing inference.

\section{Blockchain Technology and Organizational Learning Effectiveness}

Blockchain technology can be equally beneficial and applicable fort the education sector and learning effectiveness as it is proving its validity and applicability in marketing and managerial assignments[15, 22, 23]. It is being used for new pedagogy development, student records, student cost and funds, admission, registrar and student services, academics, accreditation, library, finance, marketing, institutional research, legal issue, human resource management and meta-university analysis [16, 24]. It is used in revamping the knowledge reward system, making credentials more credible and keeping records safe and easily accessible in the cloud. Blockchain for education may be a new concept, but technologists already see a myriad of possibilities. Still, there are others who find more questions than answers - and understandably so[25]. Much of what we know about blockchain today is based on our knowledge of or experience with Bitcoin. And given regulatory barriers and the bureaucratic intricacies of most school systems, it's hard to predict whether educational institutions will adopt the technology. But you have to remember that most of the groundbreaking concepts we enjoy todaythe internet, outsourcing, telecommuting, online payment processing, and even eLearning-were met with the same initial trepidation[26, 27]. So, while the future of blockchain in education is hard to say with pinpoint accuracy, from this vantage point, it definitely looks exciting $[19,28]$.

\section{$3 \quad$ IS and Organizational Learning in Universities: Impact on Employees}

Opponents have labelled IS use for learning and innovation stressful and distracting, arguing that it 'sweats' knowledge workers, as it demands faster work processes, change the role and nature of job, produce more social pressure and control and also IS based projects implementation leads toward reduction of labor force. Moreover, IS also demands more production and efficient working processing in less time[7]. Different researchers claim that IS can be used as a best management tool and strategy to relegate unions through selecting their influential and positional knowledge workers and making 
them the part of the management and change implementing body, then the resistance can be bitterly encountered[16, 29]. Similarly, [15, 30]findings also support that organizational cynicism for change can be tackled when the resisting groups and unions are taken on board. Similarly, knowledge workers and the positional faculty member can be enriched with the context of IS, that it contains flexible learning and production systems and sub-routines. IS also promote participatory learning approach, best sharing, storing and disseminating mechanism for centralized as well as modularized learning, which boost individual and organizational learning, develop their skills and abilities, improve employee commitment intrinsically as well as extrinsically[29]. Although, during review process, we came over certain research findings with discouraging results on the part of IS installation for organizational learning, but it differs from organization to organizations, their expertise and context matter the most. But with the passage of time, new software and hardware are coming in use, which are capable for capturing organizational and individual knowledge and experiences, which can be further used for individual empowerment and organizational development[12].

For an organizational learning, Information System (IS) is an attractive initiative to university leaders and faculty facing major challenges in difficult contextual learning and their interpretation. As $[9,15]$ argue, IS programs contain desire services and subroutines to fulfill the desire of policy makers to reorganize teaching-learning process and managerial techniques for better throughputs. In Pakistan, many IS initiatives have been taken in educational domains, but they were of smaller scope and size, focusing on the small scale operant problems[19]. Due to their limited scope and size, these projects were not in a position to be made generalized for developing effecting teachinglearning processes and managerial techniques for sustainable organizational learning and development[14]. There were certain bottlenecks for the IS orientation and implementation for the organizational learning and development, out of the them, lack of continual learning culture in the learning organization, quality deployments and enhancement cells, low commitment of the leaders and managers, availability of the resources in the form of man, money and materials, poor communication strategies and government support if the form of law and regulations[23, 29]. Moreover, based on a study of large universities in the developed countries like UK, Cartwright [24] reported that IS was initially considered as a beacon of hope for the learning purposes, but later it was obsoleted for the said purpose, which created fuss in the further IS projects for learning and managerial orientations in the learning environment.[22, 29]. In contrast, different studies have found that some IS projects has changed the learning and management philosophy for individual as well as organizations, has improved quality of leaning phenomenon in the paper-less environment, has engaged knowledge workers and faculty in productive commitments, has increased the number of participation, control and the promotion of organizational learning and development[14, 23]. The second part of the research is that how senior and positional faculty members can manage and control workplace innovation and changes during the orientation and implementation phase of the information system for learning and managerial processes. Therefore, the research focused on those faculty members, who were engaged in hybrid role of management and instructional commitments. 


\section{$4 \quad$ Institutional Work}

Lawrence and Suddaby [16] define IW as focused action of the individual and organization to create, maintain and disrupt organizations, their management and operations. Its main focus is on the continues institutional improvements and transformation, quality enhancements, building the efficacy, efficiencies and productivity of the learning organization. Main focus of the IW is to brings such change agents to the center phase of institutional work theory, and considering them the principal drivers of institutional change and 'the stabilizing guardian' [31].

According to Belle $[12,17]$ organizations are core of structure procedure, norms, values and socio-cognitive assets that, aligned in coherent manner for defined targets and objectives actions and assets, which provide soul and blood to the organizational and individual lives. Focus of the defined procedures are to define regulatory laws and procedure for the development of the controlled environment. Norms are developed for the to develop harmony and protocols for organizational elements. Similarly, the sociocognitive elements work for the social, emotional, psychological ethical and cognitive development of the organization for sustainable development of the organizations, which sense the inside and outside environment and do active response planning for its transformation to create value for their stakeholder. Belle also argues that the sociocognitive element of the organization shared understanding and vision among the internal and external elements for the defined objectives.

Organizational approach is principally valuable in learning organization like universities, where the change agents are found in a conflict regarding defining the shared vision and objective for the organizational transformation valuing their interests through inserting positional powers and most of the time show cynicism to change. $[11,16]$ state that in larger and complex organization like universities organizational change is impeded through peer pressure via inside and outside relations, both vertically and horizontally. But the change agent, strive their best for the transformation of the organization in canvas of defined laws, regulations while keeping in view the larger interests of its stakeholders through logics and super-logics and taking all interest groups on board[26]. The change agents bring changes in organization, firstly through advocating, educating, and persuading the major stakeholders and positional elements. Secondly, for organizational transformation and development, continuous plans, projects and policies are formulated through consistent feedback from the internal and external sources and at the same time coherent liaison are maintained among the workers and groups for the uplifting of the organization. Moreover, the records of the disrupting operations and management are made benchmark to get insight from them for further development[28].

The IW framework also develop protocols and working boundaries for individual and group in the organization to avoid role conflict[15]. Role identification and interplay of the boundaries, practices are the norm of the learning organization, because it developed matured and defined social and working contact among the organizational elements. Moreover, it also keeps close eyes on the exogenous events, translate and contextualize them in the organizational domain. According to social constructivists, this process give birth to the production, revising and reproduction of the learning and 
knowledge, which are used for organizational learning, transformation and development $[31,32]$. Active contact and contextualization of the field knowledge create motivation among the knowledge workers, which further enhance organizational learning and development[2]. [8,10] argue that in translation and contextualization of the external knowledge, both facilitator and impeders paly their role. Its effects organization at individual level, organizational level and professional level. At individual level, domain expertise, content knowledge, autonomy and professional traits can play active role in change introduction and work place innovation. At organizational level, the strategic vision, structure, strategies, culture, norms and management system define change and innovation. Similarly, the professional associations and unions, can play active role, both as an impeders and facilitator in the organizational change and development.

\section{The Power of The University Profession}

According to J.Coopy $[2,8]$ a knowledge worker or professional is the compositions of skills, qualifications, certain traits and experiences. From an exclusive identity through socialization process, it creates social identity and do professional progression development. University faculty (professors) are generally viewed as the most influential profession in university, they are the part of the decision making process, therefore paly active role and university projection and policy level. They decide that who is admitted to the program, what kind module, course and method should be applied to engage them in teaching learning and also the managerial processes. They can play a critical role in organizational innovation, development, effectiveness and learning that could impact not directly not only on students, but also on the society and economy as a whole. Professors are trained to be independent in the contextual domain for the teaching learning processes and research, rely on their own judgment and tend to identify with their profession rather than the organization[14, 31]. Historically, faculty at university level have resisted new ways of organizing teaching-learning processes and new research methods, which can challenge their professional dominance and autonomy [1]. The introduction of information system based process redesign can be interpreted as a challenge to their autonomy[7].

The theory of IW also urge that, the change agents are influenced by their positional powers and the control of the resources[28]. They have the ability to adopt or impede any kind of change. In Pakistan, professors, most of the time have resisted for change to maintain their privileged position[15]. According to Hardy and Cartwright [12], privileged actors never welcome change and novelty, because they are deeply used to with the existing system, they are favored by the existing system and change can be a threat for their dominancy[4]. Belle [16] argues that senior stakeholders and professionals remain the most influential elements in the cotemporary organizational changes and innovation. IW also gives rationale that they should be heard even guaranteed for the position and dominancy for the learning and transformation of the organization. These professional can be engaged in professional projects and plans, and remain engage consciously or unconsciously in organizational development and transformation[28]. Based on UK evidence, Sutcliffe \& Court $[7,11]$ proclaims that when faculty feels 
threats from managerial and leadership cadre in the form of delegating their powers, changing routine tasks, reallocation if the resources and tasks, shifting controlling mechanism, definition of new spaces, populating their space with new people, then they impede the innovation and work place change. They can be managed via rational and super logic for their convincing and persuasion, or new program can be legitimate or delegitimize for the social and organizational acceptance[11]. Furthermore, faculty member working on the hybrid roles, have to manage their operational and strategic duties, for the sustainability, maintainability, and transformation of the organization, therefore they have to accept the change formally or informally for the future concern. Moreover it become the part of their job portfolio and their major concern become organizational transformation and learning development[13, 30]. How they do this is a focus of this paper.

\section{The Research Context: Institutions and Institutional Actors}

In Pakistan, public universities are operated and financed by state and federal governments. Therefore, public universities have immediate responsibility for the services provision in educational settings, which is based on funding agreement and performance measure. Furthermore, they also keep liaison for the institutional development with the larger industries through occupational agreements. Many projects and programs are initiated with manufacturing, construction and health industries, where social and technological demands are contextualized. In public universities, most of the projects are developed on public feedbacks, social and industrial relation, which not only pave the road for organizational development and transformation, but also for the social development as a whole. Similarly, employment negotiation is based on the public interests, where it become incumbent for them to do further development. These roles and responsibilities become milestone for the organizational learning, transformation and workplace innovation. All these comes under the obligatory roles of the key change agents; just enthusiastic attitude of the knowledge worker is needed.

Similar to public universities, private universities are governed and operated at federal and provincial level, under the regulation of HEC. Again, the majority of university staff are employed directly by the university their selves, on employment contracts, many of whom are independent contractors who claim fee-for-service reimbursement from their respective universities at provincial or federal level [1, 12]. Private sector universities are supposed to follow government law and they also wish for transformation and development of the organizations otherwise they may not be able for facing the pace [33].

In both public and private universities, professors are generally represented through their association and unions. In both cases, they develop these associations for professional development, organizational enhancement and membership associations rather than as unions, but in practice they conduct many of the roles of unions such as bargaining and lobbying. In both cases, their associations have considerable influence, so governments often aim to co-opt these organizations into planning and educational reform processes. 


\section{$7 \quad$ Methodology}

In line with [14] for data analysis we used multilevel interdisciplinary approach. Current and historical data from two different universities was collected. Data was extracted from organizational manuals, workplace observation, report scanning, semistructure interviews, policy and projects plans, government reports and other related documents.

In this paper, we examine retrospectively process redesign projects implemented in the information system (computer sciences) Departments of a large two different universities, one from public and one from private sector for the contextual (cognitive, social and behavioral) learning and their role in organizational effectiveness and development. It was observed that the usage of information system and block chain have improved the capacity and capability for learning at organizational level, although, the process is bit slow and immature. Moreover, it is also adding and expanding capacity and increasing speed of throughput and sustainability [15, 34]. In Public Sector University, the study included an analysis of the block chain technology and information system project implemented for capturing learning contextual to the organization that may be cognitive, social and behavioral addition, in 12-month period, during 20172018. Similarly, in the private sector university, study included a 2016-2017 of the same duration. Both projects aimed to increase the rate of flow and capturing the tacit, explicit, cognitive, social and behavioral aspects of learning in the information system department.

In Public Sector University, during 2017-2018, interviews with 47 key informants and stakeholders were conducted, who were having detailed understanding of the projects orientations and implementations. Among interviewees, we approached senior faculty members, program directors, academic coordinators and hybrid role professionals. Beside this $\mathrm{PhD}$ research scholar were also were also investigated about the impact of the completed projects. In Private Sector University, 32 professionals were approached to assess the impact of the projects. Snow ball sampling was used to, starting from key informer, knowledge workers and senior profession and heading towards facilitators and impeders. The designed questions focused on the perception of the information system and block chain processes and outcomes for organizational learning and development. As per recommendations of the previous studies, three coders were employed for data collection and content analysis.

\section{$8 \quad$ Findings: Information System and Block Chain in Universities for Organizational Learning Effectiveness}

Both universities in this study implemented information system and block chain for the organizational learning effectiveness and organizational development and to bring improvement in organizational learning and development to envision their knowledge workers to be more productive and efficient. These projects really improved the learning capturing processes, which were integrated in the learning repository of the universities and met the workers as well as their stakeholders' needs and expectation. In the 
public university, the voice-chancellor and the dean faculty of numerical sciences played a major role in driving the initiative. In the private sector university, however, the project to implement IS for the organizational learning and effectiveness was driven by the post graduate research student with some of their faculty members of the information system department.

In these projects, universities were also supported by the ministry of education and other sister organizations working for the organizational development. But these processes need updating from time to time with the change in the social and environmental demands and with the infusion of new technological advancement. Accordingly, the faculty members, admin staff and other knowledge workers are supposed to be trained in the learning modules, so that the organizations can benefits in the best possible and viable way from these projects. Moreover, the quality assurance department is supposed to design and maintain a mechanism for smooth operations of the learning project and repository should be made available for all stakeholder to be their beneficiaries. Similarly, different unions and groups are supposed to be negotiated for getting the desired objectives of the projects, so that any kind of anomalies and redundancies are minimized.

\section{Conclusion and Future Recommendations}

Information system carries the capacity to capture, store, disseminate and integrate the information and learning processes. Therefore, all the learning organizations like university are supposed to devise a mechanism for the capturing, storing and disseminating information and learning packets among their knowledge workers for the best optimal, effective and productive performance. In universities, libraries, labs, offices and even lounge can be upgraded with the information system tools, software and hardware, which can be used for the capturing of organizational knowledge and experiences. Moreover, further research is recommended to explore the use of the block chain technology for the organizational learning effectiveness and development. Block chain technology can be utilized for the learning and managerial system and decision making processes, which will give new horizons not only to organizational learning, but will boost organizational profile. Their management, marketing and other department's activities and operations will be synchronized.

\section{Acknowledgement}

The authors would like to convey a special thank you to Universiti Malaysia Pahang for its financial support through RDU172208 flagship grant for this paper. 


\section{References}

[1] Bavarsad, B., F. Rahimi, and M. Seyfi, A Study of the Relationship between Organizational Learning, Strategic Flexibility, Competitive Strategy and Firm's Performance. International Journal of Psychology and Behavioral Research. Vol., 3(3), 2014: p. 198-210.

[2] Belle, S., Organizational learning? Look again. The Learning Organization, 2016: p. 332 341. https://doi.org/10.1108/tlo-01-2016-0007

[3] Frees, W., W.v. Acker, and G. Bouckaert, the role of Feedback, Accountability and Learning in Organizational Change and Innovation: A theoretical framework. 2014, LIPSE: $m$ the European Union's Belgium.

[4] Argyris, Single-Loop and Double-Loop Models in Research on Decision Making. Administrative Science Quarterly, 1976: p. 363-375. https://doi.org/10.2307/2391848

[5] Kantamara, P. and V.V. Ractham, SINGLE-LOOP vs. DOUBLE-LOOP LEARNING: AN OBSTACLE OR A SUCCESS FACTOR FOR ORGANIZATIONAL LEARNING. International Journal of Education and Re-search 2014: p. 55-63.

[6] J.Coopy, Learning to trust and trusting to learn: a role for radical theatre. Management Learning, 1998: p. 365-382. https://doi.org/10.1177/1350507698293006

[7] Cartwright, S., Double-Loop Learning: A Concept and Process for Leadership Educators Journal of Leadership Education, 2002: p. 68-72.

[8] VajihehSaadat and ZeynabSaadat, Organizational Learning as a Key Role of Organizational Success. Procedia - Social and Behavioral Sciences Volume 230, Is-sue 12 2016: p. 219225. https://doi.org/10.1016/j.sbspro.2016.09.028

[9] Geus, A.d., Modes of Organizational Learning. 2011, Kollner Gropu: UK.

[10] Miertschin, S.L., B.L. Stewart, and C.E. Goodson. Mobile Devices and Lifelong Learning: The Students' Perspective. in ASEE Annual Conference \& Exposition. 2016. Louisiana: ASEE. https://doi.org/10.18260/p.25736

[11] Pimmer, C., N. Pachler, and G. Attwell, Towards Work-based Mobile learning: What We Can learn from the Fields of Work-based learning and Mobile learning. International Journal of Mobile and Blended Learning, 2(4), 2010: p. 1-18. https://doi.org/10.4018/jmbl. 2010100101

[12] Hameed, N., Mobile Learning Readiness in Higher Education in Pakistan. 2014, Abbottabad: COMSATS institute of Information Technology.

[13] Send in the Reinforcements: How the Mobile Revolution can Overcome the For-getting Curve. 2017, Swiss VBS: Ontario.

[14] Alhabeeb, A. and J. Rowley, Critical success factors for eLearning in Saudi Arabian universities. International Journal of Educational Management, Vol. 31 Issue: 2, 2017: p. 131-147. https://doi.org/10.1108/ijem-01-2016-0006

[15] Attwell, G., Work-Based Mobile Learning Environments: Contributing to a Socio-Cultural Ecology of Mobile Learning. International Journal of Mobile and Blended Learning, 2(4), 2010: p. 19-34. https://doi.org/10.4018/jmbl.2010100102

[16] Beck, R. and C. Müller-Bloch. Blockchain as Radical Innovation: A Framework for Engaging with Distributed Ledgers as Incumbent Organization. in Proceedings of the 50th Hawaii International Conference on System Sciences. 2017. Copenhagen: IT University of Copenhagen. https://doi.org/10.24251/hicss.2017.653

[17] Fuenfschilling, L., F. Geels, and R. Raven, An institutional perspective on sustainability transition. 2014, Lund University: UK.

[18] Pachler, N. and J. Seipold, mobile learning cultures across education, work and lei-sure. 2009, London: WLE Centre.

[19] Spindell, A., Mobile Learning: Getting Started. 2014, edChunk Inc. 
[20] Cheon, J., et al., An Investigation of Mobile Learning Readiness and Design Considerations for Higher Education. 2015, Texas Tech University: Texas

[21] Zeng, Y., Evaluation of Physical Education Teaching Quality in Colleges Based on the Hybrid Technology of Data Mining and Hidden Markov Model. International Journal of Emerging Technologies in Learning (iJET), 2020. 15(01): p. 4-15. https://doi.org/10. 3991/ijet.v15i01.12533

[22] Khosravania, Deyreh, and Karami, Does organizational forgetting matter? Organizational survival for life coaching companies. The Learning Organization, Vol. 22 Issue: 3, 2015: p. 150-162. https://doi.org/10.1108/tlo-12-2014-0068

[23] Briz-Ponce, L., et al., Learning with mobile technologies - Students' behavior. Computers in Human Behavior Volume 72, 2017: p. 612-620. https://doi.org/10.1016/j.chb.2016.05. $\underline{027}$

[24] Turi, J.A., et al., The Cognitive, Behavioral and Social and Prospectives of Organizational Learning Through Information System. Malaysian Online Journal of Educational Management, vol 6, issue 3, 2018: p. 68-86. https://doi.org/10.22452/mojem.vol6no3.4

[25] L.Vargoa, S., H.W. Meliss, and A. Akak, Innovation through institutionalization: A service ecosystems perspective. Industrial Marketing Management Volume 44, 2015: p. 63-72. https://doi.org/10.1016/j.indmarman.2014.10.008

[26] Wallenburg, I., et al., Repairing reforms and transforming professional practices: a mixedmethods analysis of surgical training reform. Journal of Professions and Organization, Volume 3, Issue 1, https://doi.org/10.1093/jpo/jov012, 2016: p. 86-102. https://doi.org/10. 1093/jpo/jov012

[27] Bdiwi, R., et al. Towards a New Ubiquitous Learning Environment Based on Blockchain Technology. in IEEE 17th International Conference on Advanced Learning Technologies. 2017. Timisoara: IEEE. https://doi.org/10.1109/icalt.2017.37

[28] Lawrence, T. and R. Suddaby, Institutions and Institutional Work. 2006, UK University of Oxford.

[29] Aydin, E. and A.S. Gormus, Does organizational forgetting matter? Organizational survival for life coaching companies. The Learning Organization, Vol. 22 Issue: 3, 2015: p. 150-162. https://doi.org/10.1108/tlo-12-2014-0068

[30] Al-Mamary, Y.H., A. Shamsuddin, and N. Aziati, The Meaning of Management Information Systems and its Role in Telecommunication Companies in Yemen. American Journal of Software Engineering, 2014: p. 22-25.

[31] Ahadi, S., Relationship between Empowerment and Organizational Learning among Academics in Malaysian Research Universities. Journal of Business Management, vol.22, issue.2, 2011: p. 226-241.

[32] Azer, M. and A. El-Sherbini, Cultural challenges in developing e-learning content. International Journal of Emerging Technologies in Learning (iJET), 2011. 6(1): p. 11-14. https:// doi.org/10.3991/ijet.v6i1.1467

[33] Wong, K.-T. and N. binti Abdullah, Exploring the Drivers of Intention to Use Inter-active Whiteboards among Malaysia University Students: Does Technology Self-Efficacy Matter? International Journal of Emerging Technologies in Learning (iJET), 2020. 15(01): p. 163175. https://doi.org/10.3991/ijet.v15i01.11497

[34] Waris, M., et al., An Application of Analytic Hierarchy Process (AHP) for Sustain-able Procurement of Construction Equipment: Multicriteria-Based Decision Framework for Malaysia. Mathematical Problems in Engineering, 2019. 2019. https://doi.org/10.1155/ $\underline{2019 / 6391431}$ 


\section{Authors}

Dr. Jamshid Ali Turi, is an Assistant Professor at the Department of Management Sciences, SZABIST Larkana Campus, Larkana, Pakistan. He is a young and optimistic researcher, has published a dozen of papers and addresses dozens of national and international research conferences. jamshidump@gmail.com

Dr. Alaeldeen Al Adresi hold PhD Degree in Industrial Management. He is a postdoctoral fellow at the faculty of industrial management, University Malaysia Pahang, Malaysia. His area of research includes blockchain technologies, sustainability and human resource management practices.

Associate Professor Dr. Mohd Ridzuan Darun, is a Chief Operating Officer/ Registrar of University Malaysia Pahang. He is a renowned researcher. He has been a dean of Faculty of Industrial Management, University Malaysia Pahang. He has produced many $\mathrm{PhD}$ and Masters Scholar and has been contributing in his capacity to the body of knowledge.mridzuandump@ump.edu.my

Senior Lecturer Dr. Fatimah Binti Mahmud is head of program of Industrial Management. She is a promising researcher and has produced a number of $\mathrm{PhD}$ and Master Scholars. Beside this, she has addressed a number of national and international research conferences, and research papers. fatimahm@ump.edu.my

Article submitted 2019-12-12. Resubmitted 2020-03-02. Final acceptance 2020-03-03. Final version published as submitted by the authors. 